\title{
TRAJETÓRIAS DE PESQUISA, TRAJETÓRIAS DE VIDA: EXPERIÊNCIA E CONSTITUIÇÃO DE UM PESQUISADOR
}

\author{
Roney Polato de Castro ${ }^{1}$
}

Resumo: $O$ artigo se propõe a discutir elementos que constituiriam o que nomeamos como pesquisa-experiência, inspirado nas teorizações sobre experiência de Jorge Larrosa e Michel Foucault. Busca apresentar tal perspectiva intimamente vinculada a processos de pesquisa vividos pelo autor em suas trajetórias pela pós-graduação. Retomando argumentações construídas em uma tese de doutorado em Educação, com foco na formação docente enquanto formação-experiência e formação ética-estética-política, o artigo investe no atravessamento entre trajetória de vida e de pesquisa, tendo em vista a potencialidade dessa experiência na constituição de um sujeito pesquisador.

Palavras-chave: experiência; pesquisa-experiência; Michel Foucault; pesquisa em educação; (des)subjetivação.

1 Introduzindo a questão: delineando pistas de uma pesquisa-experiência

O que nos conduz à pós-graduação? Essa é uma questão que tenho instigado minhas orientandas/os de mestrado e doutorado a se fazerem na ocasião em que redigem suas dissertações e teses. A partir daí emergem diferentes relatos que narram as experiências que vão constituindo e, sobretudo, incomodando as pessoas, a tal ponto que isso se torna, efetivamente, uma questão. Tomar essa trajetória como algo a ser pensado diz de um investimento na construção da pesquisa, já que nossas aproximações com o tema, com o objeto de estudo, com as perspectivas teórico-metodológicas que incorporamos, têm íntima relação com nossas experiências enquanto seres no mundo, que vão se afetando e se moldando. Assim, temos experiências no âmbito de vivências pessoais e familiares; experiências no âmbito acadêmico, especialmente aquelas vivenciadas em ações de formação nos cursos de graduação; e as experiências profissionais, algo que se tornou comum em se tratando de um programa de pós-graduação em educação.

A partir de um convite para participar do Seminário Permanente de Pesquisa do Programa de Pós-graduação em Educação da Universidade Federal de Juiz de Fora, pude retomar esse investimento narrativo e buscar olhar para trás, para o percurso que vim construindo até o momento no que se refere às inquietações que me trouxeram para a pós-graduação, para a pesquisa. Olhar para trás é uma ação de quem retoma uma trajetória, podendo vinculá-la a um processo de constituição de si e, sobretudo, de transformação de si. Inspirado em Michel Foucault (2009) e em Jorge Larrosa (2014),

\footnotetext{
${ }^{1}$ Doutor e Mestre em Educação, Licenciado em Ciências Biológicas. Professor da Faculdade de Educação e do Programa de Pós-graduação em Educação da Universidade Federal de Juiz de Fora. Membro do grupo GESED grupo de estudos e pesquisas em Gênero, Sexualidade, Educação e Diversidade. E-mail: roneypolato@gmail.com.
} 
penso em pesquisas-experiências, produção de experiência com a pesquisa. Em minha tese de doutorado (CASTRO, 2014) operei com a ideia de experiência como

\begin{abstract}
algo que (nos) acontece e que às vezes treme, ou vibra, algo que nos faz pensar, algo que nos faz sofrer ou gozar, algo que luta pela expressão, e que às vezes, algumas vezes, quando cai em mãos de alguém capaz de dar forma a esse tremor, então, somente então, se converte em canto. E esse canto atravessa o tempo e o espaço. $E$ ressoa em outras experiências e em outros tremores e em outros cantos" (LARROSA, 2014, p. 10).
\end{abstract}

A experiência tem algo de paixão, de padecimento, de conversão. Rompendo com um sentido de experiência como 'experimento", pautada nos rituais de uma Ciência inventada como verdade que explica o mundo, o experienciar estaria mais próximo do ser afetado e ser transformado pela experiência (CASTRO, 2014). Portanto, se trata de pensar modos de pesquisa que não tomam a experiência como 'conhecimento inferior', como obstáculo para uma 'verdadeira ciência'. Diz, portanto, de um processo, por vezes intranquilo, confuso, ligado à fugacidade e mutabilidade do tempo, algo que não depende de nós, ou seja, sobre o qual temos pouco controle (LARROSA, 2014). Importante destacar que uma pesquisa-experiência não se remete a processos de controle de fenômenos para então decifrá-los e produzir sobre eles uma verdade, a intenção não é reivindicá-la como experimento e como autoridade, em suas conotações empíricas e dogmáticas.

A experiência com a pesquisa começa quando algo nos acontece, mesmo que não saibamos o que nos acontece, portanto, não depende de nosso saber, poder ou vontade (LARROSA, 2014). Sendo sempre de alguém, a experiência é subjetiva e provisória, constituindo subjetividades em curso, assim, tem a ver com o que nos faz ser quem somos e no que nos faz transformar o que somos. Daí a perspectiva de uma pesquisa-experiência que pode modificar os modos de olhar para determinados fenômenos, para objetos de investigação até então naturalizados, nos tornando capazes de estranhar o que somos, o que vemos e percebemos do mundo.

Larrosa (2011), ao tomar a experiência como princípio de subjetividade, ou seja, que diz de um sujeito, suas ideias e visões de mundo, nos conduz a pensá-la como princípio de transformação, que supõe dois movimentos: de ida - de saída de mim mesmo, ao encontro do que me passa; de volta de retorno a mim a partir dos efeitos do acontecimento que é a experiência sobre mim, o que sou, o que penso. Podemos pensar que tal princípio se potencializa tanto mais o sujeito esteja aberto, sensível às transformações. Por isso, para Larrosa (2014), a experiência não se dá sem risco, sem o perigo de que o percurso produza um outro de mim mesmo. O sujeito da experiência, portanto, é um sujeito exposto, um território de passagem ou uma superfície de sensibilidade, em que algo, ao passar, deixa vestígios, marcas, rastros, feridas. A pesquisa-experiência seria, assim, um processo disparado pelo modo como nos expomos ao risco de estar no mundo e nos deixar afetar pelos jogos de forças 
que compõem uma rede de negociações, contradições, alianças, tensões e resistências. Diz, portanto, de uma postura ética, de como nos colocamos nesses jogos, nesse mundo, e como nos transformamos a partir desses jogos (CASTRO, 2014). A experiência e a pesquisa-experiência envolvem, portanto, subjetivação e dessubjetivação. E com isso nos ligamos às perspectivas foucaultianas.

Em seus estudos, Foucault (2001) delineia três eixos de experiência, que dizem da produção de sujeitos: o saber, o poder e as formas de subjetividade. Ao investir em nesse percurso investigativo, o filósofo trabalha para tornar visíveis as condições de conformação dos sujeitos a partir de 'tipos particulares' de experiência. Isso quer dizer que o interesse de Foucault está no que leva os sujeitos a se reconhecerem como tal, a partir de uma experiência historicamente singular - a experiência da loucura, da delinquência, da sexualidade. A atualidade do pensamento de Foucault reside na possibilidade de pensarmos que a experiência é uma ficção, uma invenção tramada por discursos e práticas sociais de subjetivação, por jogos de verdade a partir dos quais o sujeito se pensa e se coloca no mundo.

Em nossas pesquisas nos ocupamos de visibilizar esses processos, experiências que vão constituindo sujeitos. Essa é a preocupação central de Foucault: como nos tornamos sujeitos, como nos constituímos em meio a jogos de assujeitamento e de resistências. $\mathrm{O}$ que nos leva a um outro aspecto da experiência, como modo de dessubjetivação, ou seja, como possibilidade de transformação de si, transformações experienciadas pelos sujeitos para alcançarem outras formas de ser. Para Foucault (2009), a experiência é algo capaz de 'desprender o sujeito de si mesmo, de modo que não seja mais como é, que seja completamente outro de si mesmo. Como um 'empreendimento de dessubjetivação', a experiência implica um sujeito maleável, que não assume forma fixa, mas se coloca em processo.

Tudo isso nos conduz a ideia de pesquisa-experiência. A pesquisa é tramada por alguém, um sujeito exposto a determinados atravessamentos, que dizem das vivências experienciadas em diversos âmbitos. Porém, não se trata de tomar o que nos acontece como algo dado, algo que apenas queremos confirmar. A pesquisa-experiência nos coloca no movimento de problematizar nossos processos constitutivos, de passar a olhar mais devagar, mais demoradamente, para o que nos acontece, para o que nos passa. Diz de um movimento de atenção do sujeito para consigo mesmo, para aquilo que o inquieta, que o leva a fazer perguntas, construir questionamentos, chegando mesmo a implicar-se com perspectivas teórico-metodológicas e estratégias investigativas, constituindo uma trajetória de investigação. $O$ sujeito da pesquisa-experiência vai inventando essa trajetória a partir de suas relações com o mundo, com o contexto de investigação, com as leituras que o afetam e o fazem cultivar um terreno fértil de problematizações.

$O$ conceito de problematização está intimamente relacionado com a pesquisa-experiência. $A$ partir dos estudos foucaultianos, lidamos com o conceito de problematização como ligado a ideia de 
pensamento. Pensar, para Foucault (2006a) significa 'tomar distância' em relação ao que somos, aos nossos modos de existir. O pensamento seria, assim, "liberdade em relação àquilo que se faz, o movimento pelo qual dele nos separamos, constituímo-lo como objeto e pensamo-lo como problema" (p. 231-2). James Marshall (2008), tomando o conceito de problematização para as pesquisas em educação, argumenta que ele implica "separar-se do que faz", "dar um passo atrás", estabelecer o que somos, nossas ideias, valores e práticas como objeto de pensamento, tornando-o, assim, um problema. Se a experiência envolve a modificação dos sujeitos, colocar a si mesmo como alvo de questionamento é modo de problematização de si, podendo, assim, modificar seus modos de existir, de pensar. A pesquisa-experiência tem a ver, portando, com a ação de transformar algo em problema, abrir-se às inquietações que nos conduzem ao debate, num movimento que envolve suas complicações e dificuldades, sem muitas respostas definitivas. Essa perspectiva inspira a pensar as trajetórias de pesquisa como movimentos para que nos desfaçamos de certezas, para que coloquemos sob suspeita os saberes que nos constituem e que atravessam nossos interesses de investigação.

\section{Trajetórias de vida, trajetórias de pesquisa: atravessamentos}

Assim como costumo solicitar às minhas orientandas e orientandos, na construção de minha tese (CASTRO, 2014) procurei narrar alguns dos caminhos e afetações que foram constituindo um modo de pensar a processualidade da pesquisa, a experiência na pesquisa. A pesquisa como experiência modifica e transforma quem constrói esse processo, o qual é recheado de questionamentos: que experiências nos conduzem às nossas pesquisas? Há preparação para a intensidade da experiência na pesquisa? Como pensar a pesquisa? Como pesquisar? Essas e outras questões inquietam quem se coloca como sujeito-pesquisador/a, momento em que se mesclam vários sentimentos: angústias, aflições, preocupações, alegrias, satisfações. Importante pensar que as perguntas e como as formulamos fazem parte do processo, já que com elas nos colocamos num intenso processo de busca por respostas, o qual nos lança ao movimento de mais e mais perguntas.

Nos caminhos trilhados por mim na pesquisa, múltiplas experiências foram se constituindo e se atravessando, fazendo com que eu tentasse me aproximar do que Foucault (2006a) define como "uma atitude exigente, prudente, 'experimental'", no sentido de que possa a todo o momento "confrontar o que se pensa e o que se diz com o que se faz e o que se é." (p. 219). Quando estava na graduação, cursando Ciências Biológicas, convivia com perspectivas de investigação que tomavam a pesquisa como um 'passo a passo', que visava comprovar ou refutar uma hipótese ou um resultado por vezes já verificado por outro/a pesquisador/a. Um fato fez com que eu pudesse colocar tais noções 'sob suspeita': junto à graduação, atuava como docente na Educação Básica, lidando com sujeitos nos processos de ensinar e aprender, imerso em relações sociais de poder e saber. Comecei a perceber que não se tratava de 'comprovação' ou de 'verificação', como se os dados de investigação estivessem 
ali, prontos para serem 'descobertos', à espera de um instrumento que pudesse ser verdadeiramente eficiente para torná-los perceptíveis (CASTRO, 2014).

Revendo os caminhos percorridos desde a graduação, dando um 'passo atrás' e o colocando como problema, penso que outros modos de pesquisa foram me interpelando. Foi cursando uma especialização que tive meu primeiro contato com os estudos pós-estruturalistas e foucaultianos para construir uma pesquisa em educação. Tais perspectivas, como argumentarei a posteriori, nos convocam não apenas a problematizar processos de pesquisa, mas sim a ver o mundo de outros modos. Tais experiências foram me conduzindo ao mestrado em educação (CASTRO, 2008), ocasião em que estreitei um pouco mais o contato com esses estudos, construindo outras concepções sobre pesquisa em educação. Foi um período de muitas tensões, dúvidas, descobertas e aprendizados que me fizerem estar cada vez mais convencido de que não se tratava de 'aplicar' um determinado referencial teórico a uma prática, mas, como sugere Foucault (2006a), ao invés de aplicar ideias, 'experimentá-las e modificá-las'. Com o mestrado, uma pesquisa foi efetivamente vivenciada, no contato com as escolas, com professoras, problematizando processos formativos para abordar questões de relações de gênero e sexualidades no cotidiano escolar. A questão era constituir um modo de viver com esse referencial, um modo de olhar o mundo, de tentar problematizar as tramas de poder que estavam capilarizadas nos discursos e nas práticas cotidianas das escolas, a partir das falas das professoras. Enfim, tratava-se de entender que a teoria não expressará, traduzirá ou aplicará uma prática; a teoria é uma prática (FOUCAULT, 2006a).

Ao retomar essa trajetória, percebo que a intranquilidade que habita os processos de pesquisa é um componente necessário para que nossas inquietações se mantenham ativas, portanto, a ideia não é buscar uma superação dos conflitos e tensões que nos movimentam. Parte da mudança de perspectiva envolve procurar entender que os conflitos e as negociações constituem os processos de pesquisa, assim como a própria vida. Mais conflituoso e tenso é se constituir como sujeito e como pesquisador/a por meio de perspectivas que assumem a dúvida e o questionamento como ferramentas fundamentais para movimentar as investigações. Falando de seu trabalho, Foucault (2006a) parece aproximar-se desse sentido que busco atribuir ao trabalho do/a pesquisador/a:

Quanto àqueles para quem se esforçar, começar e recomeçar, tentar, enganar-se, retomar tudo de fio a pavio, e ainda encontrar meios de hesitar a cada passo, àqueles para quem, em suma, trabalhar - ou seja, manter-se em reserva e na inquietação equivale à demissão, é evidente que não somos do mesmo planeta (p. 196).

Na trajetória do vivido com a pesquisa na pós-graduação, os tensionamentos foram se tornando especialmente visíveis em algumas situações, como nos momentos em que pude dialogar sobre os dados construídos e as análises realizadas com a investigação. Nessas ocasiões, eu costumava 
ouvir de algumas pessoas sobre suas aflições com uma falta de 'conclusão' da pesquisa, a ausência de uma resposta direta a um 'problema' da escola ou da educação, já que a ideia era que as pesquisas se sustentam pela necessidade de responder, definitivamente, a um problema, quer dizer, elas deveriam apresentar soluções. As aflições se davam em função de que minha trajetória e meus referenciais não propunham soluções, mas sim novos questionamentos e a ampliação do debate. Quando voltamos nossa atenção para o campo da educação, identificamos discursos que definem as pesquisas como apontamentos de direções 'certas' e 'seguras', sendo esperado (ou mesmo exigido) que elas tragam recomendações ou encaminhem soluções para os mais variados 'problemas', que são 'diagnosticados' por essas mesmas pesquisas. Isso coloca o/a pesquisador/a na posição de quem detém um conhecimento verdadeiro, uma verdade pretensamente sólida e autorizada (LOURO, 2007).

O término do mestrado me trouxe a possibilidade de envolvimento com processos de formação docente. Essa era uma das questões centrais que a pesquisa tinha apontado: a necessidade de colocar sob atenção e sob suspeita iniciativas de formação que pretendiam incentivar que as professoras e professores abordassem questões relativas à assim chamada 'educação sexual'. Era necessário colocar sob suspeita as ideias que essa formação mobilizava e os sujeitos-docentes que pretendia constituir. A partir dessas noções construídas com a pesquisa, pude me envolver em processos formativos diversos com professoras e professores da Educação Básica, buscando conduzir discussões no campo das relações de gênero e sexualidades, como oportunidades de colocar em ação o exercício da problematização, criando contextos em que, à moda de Foucault, era possível, talvez, pensar diferentemente do que se pensava. As reações eram as mais diversas, os afetos sentidos eram múltiplos. Um dos aprendizados com a pesquisa e com a condução desses processos formativos era que não deveria esperar que houvesse consenso, que as ideias fossem prontamente acatadas e incorporadas. Portanto, esses momentos eram de incômodos a partir da percepção de que somos produto da cultura e das relações sociais, que nossas liberdades são muito mais reguladas do que pensamos e que precisamos criar saídas para constituir subjetividades menos normatizadas.

Como discuti em minha tese de doutorado, os momentos de formação eram também para mim momentos de problematização, nos quais eu podia pensar sobre meus próprios modos de constituição e meus saberes, procurando aliar-me à perspectiva de Foucault (2006a) sobre o papel do/a intelectual: "é mudar alguma coisa no pensamento das pessoas." (p. 295). Ele mesmo argumenta que seu papel era "mostrar às pessoas que elas são muito mais livres do que pensam, que elas tomam por verdadeiros, por evidentes certos temas fabricados em um momento particular da história, e que essa pretensa evidência pode ser criticada e destruída." (Ibid.).

3 Das inquietações com a formação, uma pesquisa de doutorado se construiu 
As 'experienciações ${ }^{2 \prime}$ com a formação produziram inquietações. Dos cursos, das oficinas, das reuniões de formação eram visibilizadas questões que diziam de trajetórias de vida e de profissionalização, mas também da formação que deveria ter dado conta de saberes que pareciam 'faltar'. Ouvia de colegas docentes que a universidade pouco tratava das relações de gênero e sexualidades, que não havia uma 'preparação' para o que viriam a 'enfrentar' nas salas de aula. Meu estranhamento era em pensar no que pode a universidade em relação à formação. Esses encontros traziam questionamentos que foram se delineando como questões que, alinhavadas, foram costurando um projeto de pesquisa para o doutorado. O que significa 'estar preparado/a' para abordar essas questões na escola? Há como nos prepararmos para tal tarefa? E a universidade? Que relações teria com tal abordagem? Seria ela responsável por nos preparar? Deveríamos, como egressos/as do Ensino Superior, dar conta de todas as questões que poderiam nos chegar nos encontros que a docência proporcionaria?

Com o término do mestrado comecei a me envolver com a docência no Ensino Superior. Foi nesse momento que pude experienciar a discussão que vinha construindo com estudantes em formação. Enquanto professor substituto da Faculdade de Educação (FACED), da Universidade Federal de Juiz de Fora (UFJF), propus a disciplina opcional 'Tópicos Especiais: Gênero, Sexualidade e Educação' (TEGSE). Novas questões surgiram, novas perguntas começaram a inquietar, junto àquelas que estavam relacionadas à formação continuada. Assim, foi elaborada a proposta de investigar processos formativos na formação inicial vivida na universidade. A proposta inicial foi sendo transformada no correr do processo de pesquisa, na relação com as ${ }^{3}$ estudantes de Pedagogia, curso para o qual a disciplina opcional era oferecida. Com minha entrada na FACED como professor efetivo, um novo contexto foi se delineando: a possibilidade de pesquisar junto ao exercício da docência, como um atravessamento de experiências. Conviver com as estudantes e constituir processos de formação com elas se tornaram também questões provocativas. É dessa experiência que foi construída a questãochave da pesquisa de doutorado: Que experiências de formação docente em Pedagogia são produzidas na disciplina Tópicos Especiais: Gênero, Sexualidade e Educação?

Nesta questão de investigação uma multiplicidade de experiências se atravessa. Como escrevi na tese (CASTRO, 2014), esse atravessamento estava vivo na minha relação com as estudantes e a delas entre si: no contexto das aulas, as opiniões, as concepções, os saberes, os valores que cada um/a expressa ou silencia, as narrativas dos acontecimentos vividos que nem sempre se harmonizam - por exemplo, quando elas relatavam as relações na família, com os namorados e maridos, quando eu

\footnotetext{
2 Tentando escapar de um sentido de 'experimentação' como experimento.

${ }^{3} \mathrm{O}$ uso do feminino é proposital, como forma de marcar a presença majoritária de mulheres no curso de Pedagogia e as implicações políticas que isso nos traz para pensar a constituição social das identidades e o gênero como um organizador social.
} 
relatava casos que ouvia nos cursos de formação dos quais participava como docente. São experiências que ao serem narradas, naquele contexto, possibilitam ser problematizadas, pensadas de outros modos. Ou seja, a disciplina também criou um contexto narrativo que possibilitava colocar em questão nossos modos de constituição, como viemos nos tornamos o que somos e como era possível escapar aos assujeitamentos desses processos. Outras questões se desdobraram: como trazer para a pesquisa as experiências narradas? Como lidar com as multiplicidades de experiências como questões de pesquisa?

Retomando Jorge Larrosa e Michel Foucault, foi possível pensar que a relação das estudantes de Pedagogia com a disciplina TEGSE poderia ser uma experiência, não no sentido generalizante, de uma experiência 'da' estudante, mas de cada uma delas, portanto, uma 'passagem' singular, algo que acontece, que inquieta e pode produzir vontades de pensar, de falar, de sentir e de agir, ou como diz Larrosa (2014), de vibrar outros cantos, em outras experiências (CASTRO, 2014). Experiência que forma e transforma, ainda que não haja garantias, porque não há uma experiência a ser vivida do mesmo modo por todas. Se a experiência é uma relação com algo que me passa, que acontece a mim, com as aulas da disciplina TEGSE as estudantes podem, em relação às problematizações, se formar, se transformar, produzir suas próprias problematizações. Nesse sentido:

Importa menos o que as aulas dizem sobre os autores/as, os conceitos, e mais como
as estudantes, em relação com as palavras e conceitos desses/as autores/as, podem
formar e transformar suas palavras, suas ideias, seus saberes. Como as aulas podem
ajudar a pensar e sentir o que ainda não foi possível pensar e sentir, o que não se
queria pensar e sentir. Nessa experiência, as estudantes podem se encontrar com
suas próprias fragilidades, vulnerabilidades e ignorâncias, sua própria impotência, o
que escapa ao que sabem, ao que podem, às suas vontades. E fazer experiência,
nesse sentido, é atenção, escuta, abertura, disponibilidade, sensibilidade, exposição
(CASTRO, 2014, p. 20).

Ao longo dos quatro anos em que a pesquisa foi sendo vivida e a tese foi sendo construída, muitas experiências se produziram. A própria pesquisa foi sendo constituída no 'fazer-se'. Da primeira vez que a disciplina foi oferecida aos dias atuais, novas questões foram aparecendo, outros embates e relações. Não havia pretensão de que a tese abarcasse todas as experiências e o aparecimento de novas questões indica que a docência é um processo de constante 'inquietar-se'. Assim, uma pesquisa não pode almejar dar conta de tudo, não pode pretender capturar a complexidade dos processos de constituição de sujeitos, das relações sociais de saber-poder, das experiências singulares.

A pesquisa no doutorado possibilitou que novas conexões e novos encontros existissem. Destaco especialmente novos encontros com os temas que vinha estudando, com as perspectivas teórico-metodológicas e com Michel Foucault, oportunidade em que teci costuras entre pensar a formação docente e o cuidado de si, como ocupação consigo e constituição de uma ética de inconformidade em relação aos preconceitos, exclusões e violências. Uma formação-experiência, ideia 
inspirada em Foucault (2009), "no sentido de processos de subjetivação e dessubjetivação, 'de desprendimento do sujeito de si mesmo', - experiência da formação e da docência como desestabilizadoras de si e do mundo, de suspeita em relação às verdades prontamente aceitas" (CASTRO, 2014, p. 241).

Retomando Larrosa (2014), formação docente e experiência podem ser pensadas como princípio de subjetividade e de transformação. Na pesquisa, foi se produzindo na relação com uma disciplina que discutia questões de gênero e sexualidade. Nesse sentido, algo pode passar, algo pode acontecer a cada uma das estudantes, pode modificar seus modos de ser, de pensar, de sentir, na possibilidade da experiência e não na sua imposição. "Há transformações porque somos sujeitos e porque nosso processo constitutivo passa por formas históricas de subjetivação e dessubjetivação" (CASTRO, 2014, p. 21). A que se pensar, porém, que para cada pessoa há uma experiência singular e contextual que se faz na relação com aquilo que acontece, que toca, que the passa. Assim, deliberadamente, associei formação docente com experiência, com a possibilidade de que ela seja uma formação-experiência, "que possibilite pensar no que somos, no que viemos nos tornando, nos modos como estamos assujeitados/as a certos discursos e nas liberdades que podemos constituir diante deles." (Ibid.).

4 Trajetórias de vida e de pesquisa: sobre 'lentes' que fabricam modos de olhar para o mundo

Nesta seção, apresento alguns dos argumentos que organizam o que nomeio como as 'lentes' que possibilitaram/possibilitam não apenas instituir um percurso teórico-metodológico para conduzir minhas pesquisas, mas modos de olhar para o mundo, para as relações sociais de poder, para as práticas discursivas e não-discursivas de subjetivação. Apresento, a partir de minha tese de doutorado (CASTRO, 2014), como fui sendo escolhido por certas perspectivas, responsáveis por fabricar as lentes e por ajustá-las constantemente, já que os modos de ver e de perceber estão em constante transformação. Ao longo de minhas trajetórias de vida e pesquisa venho me aproximando dos estudos pós-estruturalistas e dos estudos foucaultianos. Tais perspectivas lançam outros/novos olhares sobre a forma como são produzidas as pesquisas em educação, sobre as implicações culturais e políticas de se fazer pesquisa, de produzir conhecimentos e sobre os efeitos políticos de verdade desses processos.

Primeiro, destaco que é importante considerar os processos de pesquisas implicados em relações de saber e poder. Como nos diz Machado (2006), “[...] saber e poder se implicam mutuamente: não há relação de poder sem constituição de um campo de saber, como também, reciprocamente, todo saber constitui novas relações de poder" (p. XXI). Pensar a produção de conhecimento como um processo em que simultaneamente se exerce o poder e se formam saberes significa localizar as pesquisas no interior de regimes de verdade que colocam em funcionamento certos discursos e certas práticas que tem efeitos, que são produtivos no sentido de criar/afirmar 
visões de mundo, de estabelecer critérios de validade para certas formas de produzir conhecimento. Como nos indica Veiga-Neto (2005, p. 141), ao estudar as articulações entre saber e poder, "Foucault descobriu que os saberes se engendram e se organizam para 'atender' a uma vontade de poder". Portanto, os saberes "se constituem com base numa vontade de poder e acabam funcionando como correias transmissoras do próprio poder a que servem".

Compreender que a realização de pesquisas e a produção de conhecimentos estão constituídas pelos jogos de saber-poder-verdade, com efeitos de poder que são codificados e regulados (FOUCAULT, 2006a), constitui a postura do pesquisador diante da pesquisa e da vida, já que, como apontam Kastrup, Tedesco e Passos (2008), "o conhecer envolve uma posição em relação ao mundo e a si mesmo, uma atitude, um ethos" (p. 12). Ao me enveredar pelos caminhos de pesquisas que discutiam formação docente, relações de gênero e sexualidades, invisto no argumento de que há uma implicação pessoal e política com essas temáticas, o que se faz por modos particulares e subjetivos de pesquisar. Dessa forma, ao fazer pesquisa é preciso definir uma política de cognição, relacionada a uma "certa maneira de estar no mundo, de habitar um território existencial e de se colocar na relação de conhecimento" (Ibid.). Tal política cognitiva está relacionada a esses caminhos pela pesquisa que se constituem a partir de experiências na docência e na pesquisa, problematizando relações de gênero e sexualidades como construções sociais, culturais, históricas e discursivas. "Assumir essa postura requer uma virada, uma reversão da atitude naturalizada, o que exige, em princípio um esforço. Mas pode se transformar numa prática, numa atitude encarnada, configurando uma nova política cognitiva" (KASTRUP, TEDESCO e PASSOS, 2008, p. 13).

Esse aspecto, portanto, diz de perspectivas que foram assumidas como possibilidade de afirmar as implicações pessoais e políticas de pesquisar a formação inicial de estudantes de Pedagogia e as relações de gênero e sexualidades. Como docente que atuava (e atua) nessa formação, que tinha (tem) uma 'atitude encarnada', trazendo para o currículo da formação inicial questões que desafiam a 'assepsia' e a pretensa neutralidade das disciplinas acadêmicas e que instauram o desafio de nos posicionarmos, estou diretamente implicado no movimento de constituição de subjetividades que a pesquisa produz. Nesse sentido é que posso argumentar que "pensamos, falamos e escrevemos a partir de determinados 'lugares' [...] móveis e instáveis, uma vez que se delineiam pela tessitura entre referenciais teóricos e interesses políticos, exigências acadêmicas e emoções" (MEYER e SOARES, 2005, p. 30). Produzir pesquisas a partir de determinados 'lugares' significa que uma pesquisa é uma investigação interessada, na medida em que "ela se desenvolve em torno de questionamentos feitos por 'alguém' (sujeito individual e coletivo), que só começa e consegue formular determinadas perguntas a partir de um lugar e em um tempo específicos" (Ibid.). Assim, não haveria um tema lá no mundo, à espera de ser encontrado e se tornar um objeto de pesquisa. Há um envolvimento direto de quem se propõe a pesquisar com o tema em questão. As experiências, quer dizer, o que nos acontece 
e o que produz alguns afetos, inscreve algumas marcas, deixa alguns vestígios, alguns efeitos (LARROSA, 2014), constituem a pesquisa.

Assim, se digo que 'fui escolhido' pelas perspectivas pós-estruturalistas e foucaultianas é porque elas me possibilitam operar com o transitório, praticar o autoquestionamento, lidar com as contradições sem me prender a um pensamento binário e oposicional, valorizar e operar com o local e o particular e com a ideia de jogos nos quais poder e resistência se exercitam (LOURO, 2007; MEYER e SOARES, 2005). Essas perspectivas são potentes constituidoras de experiências, suas proposições funcionam como ferramentas cuja função é deslocar posições de sujeito, desprender-nos de nós mesmos, de modo que funcionam como empreendimentos de dessubjetivação (FOUCAULT, 2009).

\section{Finalizando}

Trajetórias de pesquisa e trajetórias de vida estão, continuamente, em atravessamento. Os relatos e análises que compõem este texto não são capazes de apresentar, com fidedignidade, o vivido nessas trajetórias. A escrita não daria conta de capturar e cristalizar esse vivido. No entanto, como fazemos em nossos trabalhos acadêmicos, buscamos expressar com a escrita aspectos que sejam potencialmente provocadores, a fim de que as leitoras e leitores de nossos textos possam se instigar com alguns dos aspectos que nos acompanharam em nossas trajetórias.

A pesquisa-experiência, como princípio de subjetividade e transformação, implica um 'eu', que não se coloca de forma 'coerente', 'homogênea', mas cambiante, aberto e exposto às vibrações da experiência com a pesquisa. Embora a experiência seja, como propõe Larrosa (2014), singular, contextual, irrepetível, pois é 'de alguém', afetado/a por questões específicas da pesquisa, falar ou escrever na 'primeira pessoa' não significa necessariamente falar de si mesmo/a, colocar-se como 'tema' ou 'conteúdo' do que se diz, mas significa, de preferência, falar ou escrever a partir de si mesmo/a, colocando a si mesmo/a em jogo no que se diz ou pensa, expondo-se no que se diz e no que se pensa. "Falar (ou escrever) em nome próprio significa abandonar a segurança de qualquer posição enunciativa para se expor na insegurança das próprias palavras, na incerteza dos próprios pensamentos" (LARROSA, 2014, p. 70).

As escritas de nossos trabalhos acadêmicos, portanto, se produz na/com experiência, como um modo de deixar 'vazar' a experiência da pesquisa, sua intensidade. Uma escrita-experiência que ao narrar processos, caminhos, procedimentos, vivências, constitui quem escreve e quem lê. Uma escrita na dessubjetivação, que materializa certo processo de desprendimento de mim mesmo, mas que pode provocar desprendimentos outros e novas subjetivações (CASTRO, 2014). Foucault (2009) fala da produção de "livros-experiência", aqueles que ao serem produzidos são capazes de provocar transformações tais que, ao final da escrita, o/a autor/a já não é mais aquele/a que a iniciou. A partir de tais proposições foucaultianas, podemos dizer que produzimos textos-experiências (dissertações- 
experiências, teses-experiências), que nos modificam e continuam a modificar, ao materializar processos intranquilos de articulação de ideias e de diálogos com autores/as, pensar nas multiplicidades de relações entre experiências de quem pesquisa e de quem se envolve como sujeito participante desse processo. Assim, espero que este texto contribua para disparar inquietações e inspirar, talvez, outras trajetórias.

\section{Referências}

CASTRO, Roney Polato de. "Apertem os cintos"... Uma viagem pelos sentidos e possibilidades do Programa de Educação Afetivo-Sexual (PEAS). Dissertação (Mestrado - Educação). Programa de Pósgraduação em Educação, Universidade Federal de Juiz de Fora, Juiz de Fora, MG, 2008.

CASTRO, Roney Polato de. Experiência e constituição de sujeitosdocentes: relações de gênero, sexualidades e formação em Pedagogia. Tese (Doutorado - Educação). Programa de Pós-graduação em Educação, Universidade Federal de Juiz de Fora, Juiz de Fora, MG, 2014.

FOUCAULT, Michel. Tecnologías del yo. In: Tecnologías del yo y otros textos afines.

Barcelona: Paidós Ibérica S.A., 1990. p. 45-94.

FOUCAULT, Michel. História da sexualidade II: O uso dos prazeres. 9 ed. Trad. Ma Thereza da Costa Albuquerque. Rio de Janeiro: Edições Graal, 2001.

FOUCAULT, Michel. Ética, Sexualidade, Política. Ditos \& Escritos V. 2 ed. Org. Manoel Barros da Mota. Trad. Elisa Monteiro e Inês Autran Dourado Barbosa. Rio de Janeiro: Forense Universitária, 2006a.

FOUCAULT, Michel. Estratégia, Poder-Saber. Ditos \& Escritos IV. 2 ed. Org. Manoel Barros da Mota. Trad. Vera Lúcia A. Ribeiro. Rio de Janeiro: Forense Universitária, 2006b.

FOUCAULT, Michel. Cómo nace un libro-experiencia. In: FOUCAULT, M. El yo minimalista e otras conversaciones. Buenos Aires: La marca Editora, 2009. p. 09-17.

KASTRUP, Virgínia; TEDESCO, Silvia; PASSOS, Eduardo. Introdução. In: Políticas da cognição. Porto Alegre: Sulina, 2008. p. 9-17.

LARROSA, Jorge. Experiência e alteridade em educação. Reflexão e Ação, Santa Cruz do Sul, v. 19, n. 22, p. 04-27, jul./dez. 2011. Disponível em: <http://online.unisc.br/seer/index.php/reflex/article/view/2444/1898>. Acesso: 21 mar. 2014.

LARROSA, Jorge. Tremores: escritos sobre experiência. Trad.: Cristina Antunes e João Wanderley Geraldi. Belo Horizonte: Autêntica, 2014.

LOURO, Guacira L. Conhecer, pesquisar, escrever. Educação, Sociedade \& Culturas, Porto, PT, n. 25, 2007a, p. 235-245. Disponível em: <http://www.fpce.up.pt/ciie/revistaesc/ESC25/Arquivo.pdf>. Acesso: 10 fev. 2011.

MACHADO, Roberto. Por uma genealogia do poder. In: FOUCAULT, Michel. Microfísica do poder. Org. e trad. Roberto Machado. 22 ed. Rio de Janeiro: Edições Graal, 2006. p. VII-XXIII. 
MARSHALL, James D. Michel Foucault: pesquisa educacional como problematização. In: PETERS, Michael A.; BESLEY, Tina (Orgs.). Por que Foucault? Novas diretrizes para a pesquisa educacional. Porto Alegre: Artmed, 2008. p. 25-39.

MEYER, Dagmar E.; SOARES, Rosângela F. Modos de ver e de se movimentar pelos "caminhos" da pesquisa pós-estruturalista em Educação: o que podemos aprender com - e a partir de - um filme. In: COSTA, Marisa V.; BUJES, Ma Isabel E. (Orgs.). Caminhos Investigativos III: riscos e possibilidades de pesquisar nas fronteiras. Rio de Janeiro: DP\&A, 2005. p.23-44.

VEIGA-NETO, Alfredo. Foucault \& a educação. 2 ed. Belo Horizonte: Autêntica, 2005. 